\title{
О структуре тонких пленок монооксида германия
}

\author{
(C) К.Н. Астанкова ${ }^{1}$, В.А. Володин ${ }^{1,2}$, И.А. Азаров ${ }^{1,2}$ \\ ${ }^{1}$ Институт фоизики полупроводников им. А.В. Ржанова \\ Сибирского отделения Российской академии наук, \\ 630090 Новосибирск, Россия \\ ${ }^{2}$ Новосибирский государственный университет, \\ 630090 Новосибирск, Россия \\ E-mail: as-tankoff@ya.ru \\ Поступила в Редакцию 24 августа 2020 г. \\ В окончательной редакции 28 августа 2020 г. \\ Принята к публикации 28 августа 2020 г.
}

\begin{abstract}
С помощью оптических (спектроскопия комбинационного рассеяния света, инфракрасная спектроскопия, рентгеновская фотоэлектронная спектроскопия) и электронно-микроскопических методов установлено, что атомная структура пленок монооксида германия стехиометрического состава соответствует модели случайных связей, без формирования нанокластеров германия. Данная структура метастабильна и трансформируется в структуру случайной фазы при температуре $260^{\circ} \mathrm{C}$ и выше. Причиной метастабильности твердого $\mathrm{GeO}$ может являться наличие внутренних механических напряжений в атомной сетке.
\end{abstract}

Ключевые слова: монооксид германия, метастабильность, модель случайных связей.

DOI: 10.21883/FTP.2020.12.50228.9508a

\section{1. Введение}

Проведенные ранее исследования показали, что окислы германия $\left(\mathrm{GeO}_{2}\right.$ и $\left.\mathrm{GeO}_{x}\right)$ могут быть перспективны для создания мемристоров благодаря высокой плотности дефектов (вакансий кислорода), которые являются ловушками для носителей заряда $[1,2]$. Предполагают, что мемристивный эффект в окислах германия связан с образованием и аннигиляцией проводящих филаментов из кислородных вакансий при смене знака управляющего напряжения [3]. Также германиевые включения в $\mathrm{GeO}_{x}$ могут выступать как глубокие ловушки для электронов и дырок [4]. Чтобы до конца понять природу мемристивного эффекта, необходимо знать структуру $\mathrm{GeO}_{x}$. В отличие от хорошо изученных германия и диоксида германия [5], данные о структуре твердого монооксида германия практически отсутствуют в силу его метастабильности [6,7]. Как известно, при $T>200^{\circ} \mathrm{C}$ монооксид германия начинает распадаться на гетерофазную систему, состоящую из диэлектрической матрицы $\mathrm{GeO}_{2}$ с нанокластерами $\mathrm{Ge}[8]$, а при $T>400^{\circ} \mathrm{C}$ может испаряться в виде газа $\mathrm{GeO}$ [9]. Следовательно, в процессе исследования пленок $\mathrm{GeO}$ внешнее воздействие (термическое, пучком электронов, ионов, фотонов) может привести к их распаду или испарению $[10,11]$.

По литературным данным моноокись германия является аморфной $[12,13]$. Некоторые исследователи связывают аморфную структуру монооксида германия и его нерастворимость в воде с тем, что, возможно, он полимер по природе [13]. Авторы работы [6] сообщают о том, что им удалось получить кристаллический монооксид германия в виде порошка. Его кристаллы имели форму плоских квадратов, прямоугольников, реже параллелограммов. Совокупность кристаллооптических данных свидетельствует о низшей сингонии кристаллов (вероятно, моноклинной). В работе [7] синтезировали порошок монооксида германия, который оказался кристаллическим диамагнитным веществом. По мнению авторов, это свидетельствует об отсутствии в его строении олигомерных цепочек с $s p^{2}$-гибридизованными атомами $\mathrm{Ge}$, в отличие от структуры моноокиси кремния. Различие структур, вероятно, связано с наличием у атомов $\mathrm{Ge}$ $d$-электронов.

В настоящей работе исследуется атомная структура тонких пленок стехиометрического монооксида германия с помощью электронно-микроскопических и оптических методов (спектроскопия комбинационного рассеяния света (КРС), ИК-спектроскопия, рентгеновская фотоэлектронная спектроскопия (РФЭС)). Обсуждается вопрос о возможных причинах метастабильности твердого монооксида германия.

\section{2. Методика эксперимента}

Тонкие пленки монооксида германия были получены в двухстадийном процессе. На первой стадии на пластине кремния формировали композитную пленку, состоящую из смеси нанокластеров германия и диоксида германия, с предельно точным соотношением компонент $\mathrm{Ge}: \mathrm{GeO}_{2}=1: 1$ моль. Эту пленку (гетерослои $\left.\mathrm{GeO}_{2}\langle\mathrm{Ge}-\mathrm{HK}\rangle\right)$ получали в процессе химического осаждения из газовой фазы пересыщенных паров $\mathrm{GeO}$ при пониженном давлении в проточном реакторе и последующего распада твердого монооксида германия: $2 \mathrm{GeO} \rightarrow \mathrm{GeO}_{2}+\mathrm{Ge}[14]$. На второй стадии гетерослои $\mathrm{GeO}_{2}\langle\mathrm{Ge}-\mathrm{HK}\rangle$ переменной толщины $(100-400$ нм) испаряли в вакууме путем термического нагрева до температуры $550-600^{\circ} \mathrm{C}$ в течение 3-5 мин и осаждали 
пары $\mathrm{GeO}$ на холодную (находящуюся при комнатной температуре) подложку. С помощью сканирующей эллипсометрии ранее было установлено, что гетерослои $\mathrm{GeO}_{2}\langle\mathrm{Ge}-\mathrm{HK}\rangle$ полностью испаряются с подложки в ходе данного процесса. Используя данные спектральной эллипсометрии и расчеты по модели Бруггемана, была определена объемная доля аморфного кластеризованного германия и стекловидной матрицы $\mathrm{GeO}_{2}$ в гетерослое - 25 и 75\% соответственно [15]. Эти значения близки (с учетом погрешности) к значениям объемной доли германия $(\sim 30 \%)$ и $\mathrm{GeO}_{2} \quad(\sim 70 \%)$ в гетерослое, полученным из расчета молярных масс и молярных объемов, если мольное соотношение $\mathrm{Ge}$ и $\mathrm{GeO}_{2}$ составляет $1: 1$. Таким образом, можно заключить, что данный метод синтеза позволяет получать тонкие однородные пленки $\mathrm{GeO}$ стехиометрического состава. В экспериментах изучали пленки монооксида германия толщиной $\sim 10$ и $55 \mathrm{Hм}$.

Структура слоев $\mathrm{GeO}$ исследовалась с помощью просвечивающего электронного микроскопа (ПЭМ) марки JEM-2200FS с разрешением 0.19нм при ускоряющем напряжении 200 кВ в конфигурации поперечного среза.

Спектры КРС регистрировались при комнатной температуре в геометрии обратного рассеяния с помощью спектрофотометра T64000 Horiba Yobin Yvon c микро-приставкой. Для возбуждения КРС использовался $\mathrm{Ar}^{+}$-лазер с длиной волны 514.5 нм. Луч лазера был слегка расфокусирован и имел диаметр на поверхности образца $\sim 12$ мкм, мощность -2 мВт, что позволило избежать перегрева образцов и распада монооксида германия. Спектральное разрешение было не хуже чем $1.5 \mathrm{~cm}^{-1}$.

Спектры ИК-поглощения снимали при комнатной температуре на фурье-спектрометре Perkin-Elmer 2000 при спектральном разрешении $4 \mathrm{~cm}^{-1}$. Чувствительность при исследованиях на поглощение или пропускание веществом ИК-излучения обычно ограничена толщиной слоя $\sim 30$ нм, поэтому в эксперименте использовали пленки $\mathrm{GeO}$ толщиной $\sim 55$ нм.

Методом РФЭС в работе определяли стехиометрический состав пленок $\mathrm{GeO}$. РФЭС-спектры измеряли на фотоэлектронном спектрометре фирмы SPECS (Германия) с использованием полусферического анализатора PHOIBOS-150-MCD-9 и рентгеновского монохроматора FOCUS-500 (излучение $\mathrm{Al} K_{\alpha}, h v=1486.74$ эВ, 200 Вт). Образец прикреплялся на двухсторонний медный проводящий скотч. Стоит отметить, что поверхность пленки $\mathrm{GeO}$ не подвергалась травлению ионами аргона для удаления загрязнений и окисла, так как это могло привести к его распаду. Узкий спектральный регион $\mathrm{Ge} 3 d$ был измерен при энергии пропускания анализатора 10 эВ. C помощью программы XPS Peak 4.1 было проведено разложение региона Ge3d на отдельные спектральные компоненты и определен вклад каждого из состояний германия в общий спектр.

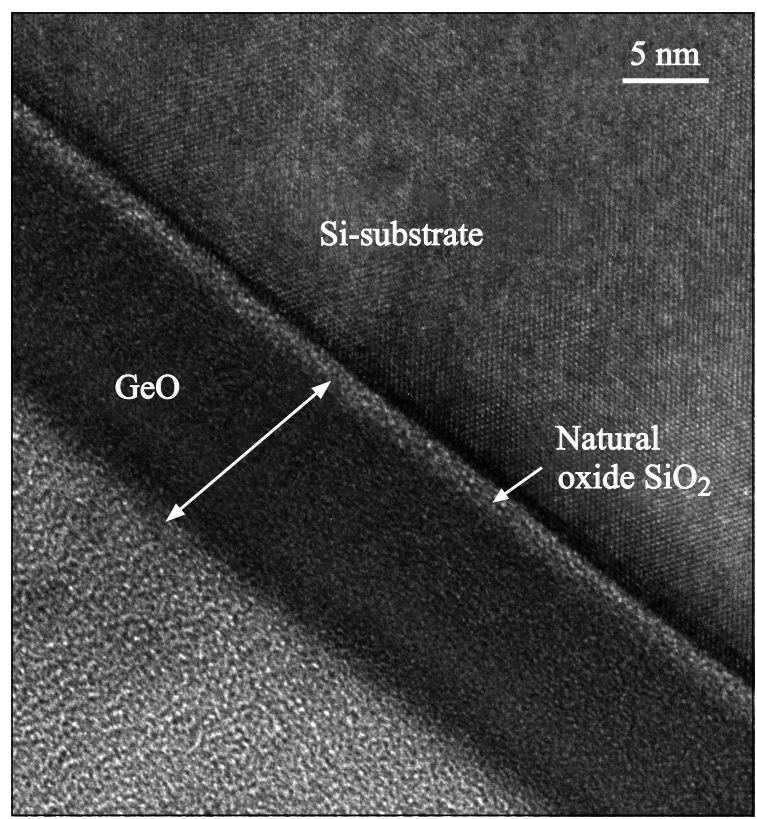

Рис. 1. ПЭМ-изображение пленки $\mathrm{GeO}$ ( 10 нм), выращенной на Si-подложке.

\section{3. Экспериментальные результаты}

Структурный анализ пленки $\mathrm{GeO}$ методом ПЭМ на поперечном срезе не обнаружил каких-либо особенностей. На рис. 1 видно, что пленка $\mathrm{GeO}$ имеет аморфную структуру, и в ней отсутствуют кластеры Ge.

В КРС-спектре пленки $\mathrm{GeO}$ в диапазоне $240-330 \mathrm{~cm}^{-1}$ не обнаружено пиков от каких-либо известных веществ (рис. 2, кривая 1). Это указывает на то, что в пленке отсутствуют связи $\mathrm{Ge}-\mathrm{Ge}$ в концентрации, достаточной для обнаружения, т. е. нет кластеров германия (согласуется с данными ПЭМ). По-видимому, как и в случае локальных связей $\mathrm{Si}-\mathrm{Si}$ [16], сечение КРС от одиночных связей $\mathrm{Ge}-\mathrm{Ge}$ гораздо меньше, чем от тех же связей, но в составе нанометрового кластера. Поэтому для их обнаружения в спектре толщина пленок должна быть на 2 порядка больше (несколько микрометров). Следует также отметить, что из всех спектров был вычтен спектр от подложки кремния, так как от монокристаллического кремния присутствует сигнал КРС в диапазоне $305 \mathrm{~cm}^{-1}$, связанный с двухфононным рассеянием на поперечных акустических модах. После кратковременного отжига пленки $\mathrm{GeO}$ в вакууме при температуре $260^{\circ} \mathrm{C}$ возникает широкая полоса вблизи 275-280 $\mathrm{cm}^{-1}$, которая соответствует рассеянию света на локальных колебаниях в аморфном германии (рис. 2, кривая 2). Таким образом, пленка $\mathrm{GeO}$ начинает распадаться на матрицу $\mathrm{GeO}_{2}$ и кластеризованный германий. При повышении температуры отжигов интенсивность данной полосы возрастает (рис. 2, кривые 3,4), что указывает на увеличение количества аморфных кластеров $\mathrm{Ge}$ в пленке $\mathrm{GeO}$. Колебания $\mathrm{Ge}-\mathrm{O}$ связей в аморфном $\mathrm{GeO}$ 


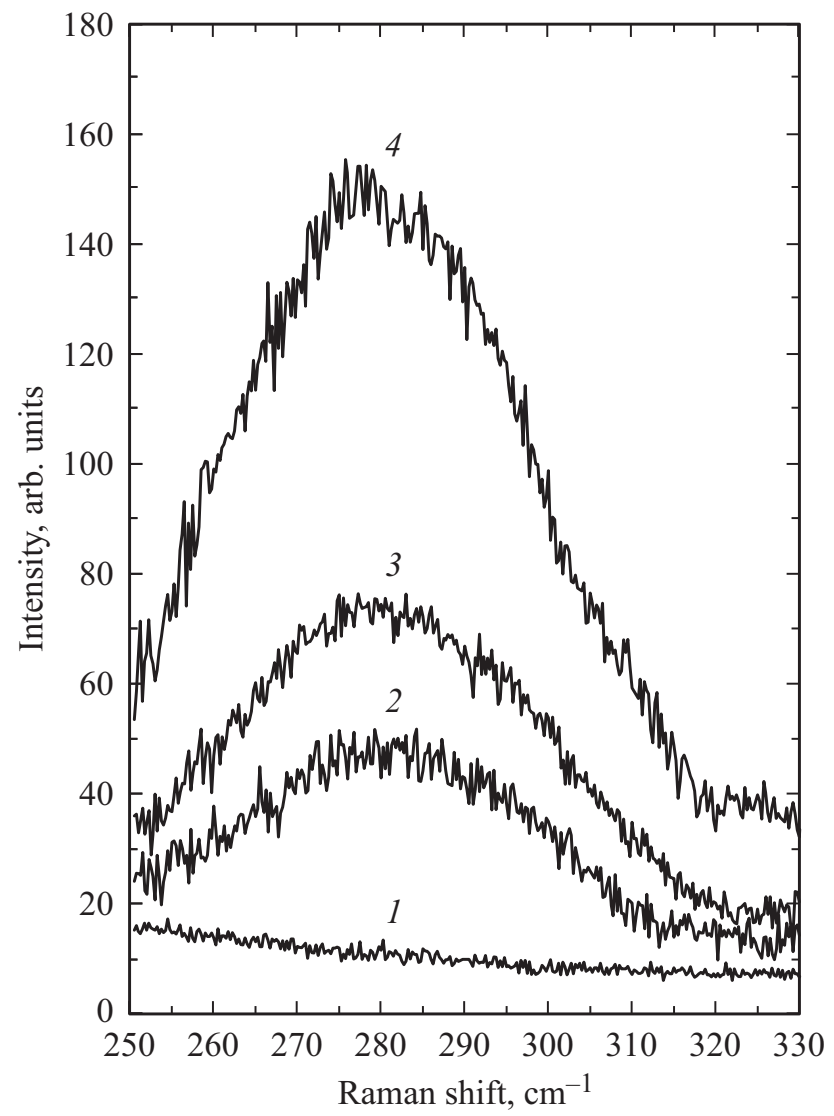

Рис. 2. Спектры КРС пленки $\mathrm{GeO}$ толщиной 55 нм: 1 - до отжига; после серии отжигов: $2-260^{\circ} \mathrm{C} / 6$ мин, 3 $290^{\circ} \mathrm{C} / 4$ мин, $4-320^{\circ} \mathrm{C} / 4$ мин.

не являются запрещенными в КРС, но их сечение крайне мало (вследствие того что КРС в данных условиях далеко от резонансного). Поэтому их лучше исследовать с помощью ИК-спектроскопии, что и было сделано далее.

В ИК-спектре поглощения пленки $\mathrm{GeO}$ обнаружена широкая полоса в области $770 \mathrm{~cm}^{-1}$ (рис. 3, кривая 1). Она соответствует валентным асимметричным колебаниям кислорода в мостике $\mathrm{Ge}-\mathrm{O}-\mathrm{Ge}$ монооксида германия $[8,12,17]$. Более слабую полосу в области $524 \mathrm{~cm}^{-1}$ приписывают изгибным колебаниям кислорода в мостике $\mathrm{Ge}-\mathrm{O}-\mathrm{Ge}$ монооксида германия [18]. Во время кратковременных отжигов пленки $\mathrm{GeO}$ в вакууме при $T=260,290,320^{\circ} \mathrm{C}$ начинается его постепенное разложение, изменяющее состав исходной пленки. На это указывает повышение интенсивности анализируемой полосы ИК-поглощения (рис. 3, кривые 2-4), связанное с появлением в слое некоторого количества аморфного $\mathrm{GeO}_{2}$, коэффициент поглощения которого выше, чем у $\mathrm{GeO}(\mathrm{тв})$. Одновременно данная полоса плавно смещается в сторону бо́льших волновых чисел, приближаясь к области $870 \mathrm{~cm}^{-1}$ - характеристической полосе ИК-поглощения стекловидного диоксида германия (рис. 3, спектр 5). Стоит отметить, что кратковременный отжиг пленки $\mathrm{GeO}$ при температуре $<260^{\circ} \mathrm{C}$ не приво- дил к изменению вида КРС- и ИК-спектров на рис. 2 (спектр 1) и на рис. 3 (спектр 1).

Спектр РФЭС 3d-электронов германия в пленке $\mathrm{GeO}$ содержит максимумы при энергиях 29.5, 31.1 и 32.8 эВ (рис. 4). Значение энергии связи наиболее интенсивного пика $32.8 \pm 0.1$ эВ характерно для германия, связанного с четырьмя атомами кислорода в составе $\mathrm{GeO}_{2}$ (тетраэдр $\mathrm{GeO}_{4}$ ) [19]. Пик со стороны меньших зна-

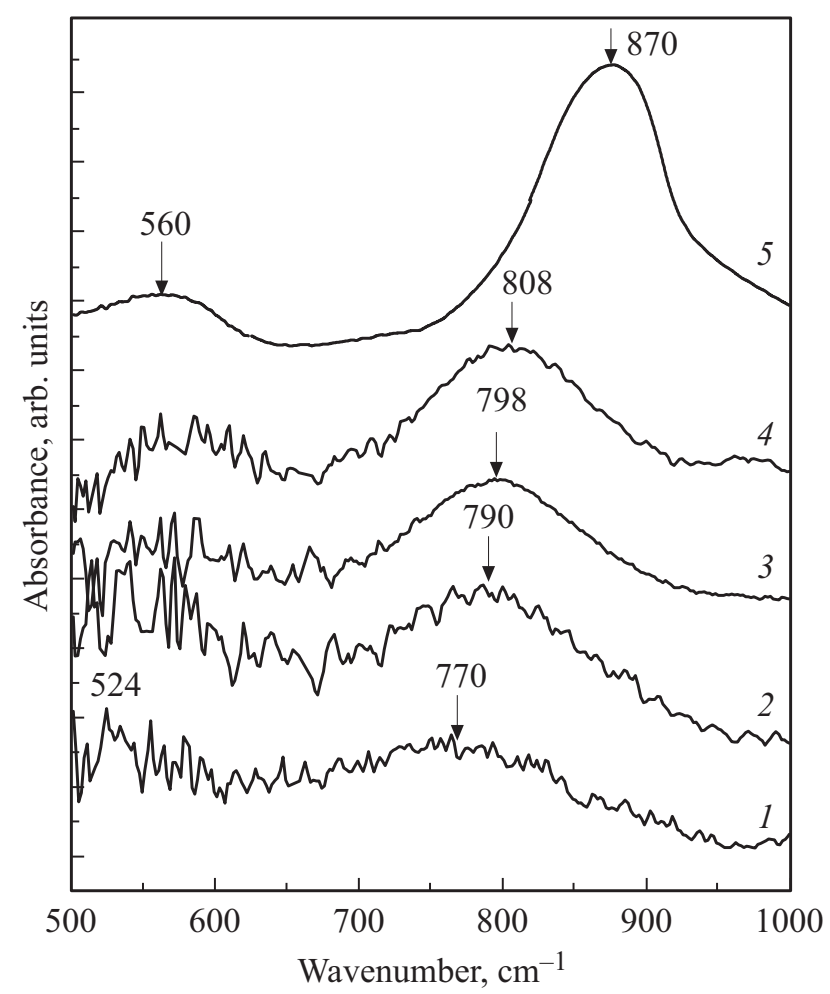

Рис. 3. ИК-спектры поглощения: 1 - исходной пленки $\mathrm{GeO}$ ( 55 нм); после отжига пленки $\mathrm{GeO}: 2-260^{\circ} \mathrm{C} / 6$ мин, $3-$ $290^{\circ} \mathrm{C} / 4$ мин, $4-320^{\circ} \mathrm{C} / 4$ мин, 5 - пленки аморфного $\mathrm{GeO}_{2}$.

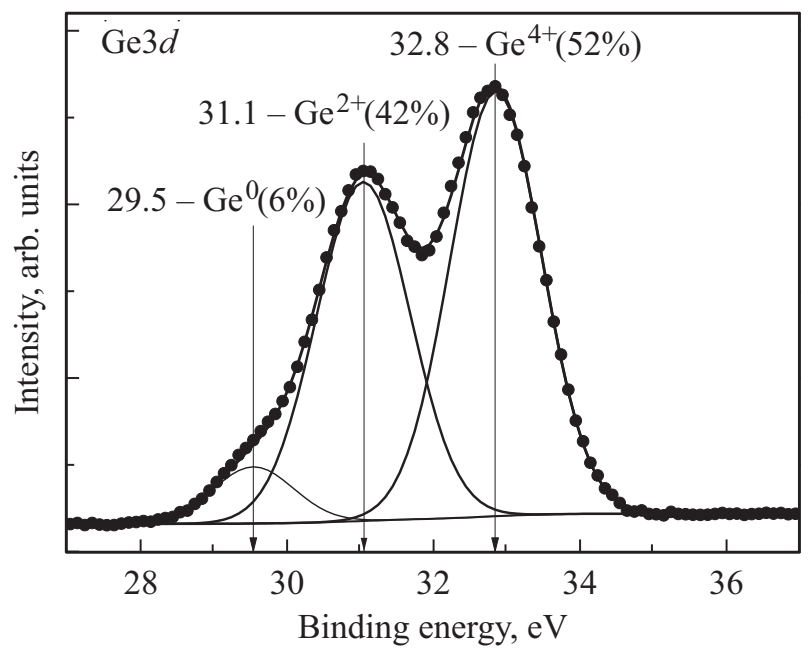

Рис. 4. РФЭС-спектр атомного $\mathrm{Ge} 3 d$-уровня в пленке $\mathrm{GeO}$ ( 10 нм $)$ на $\mathrm{Si}$-подложке. Также показана деконволюция спектра на отдельные спектральные компоненты. 


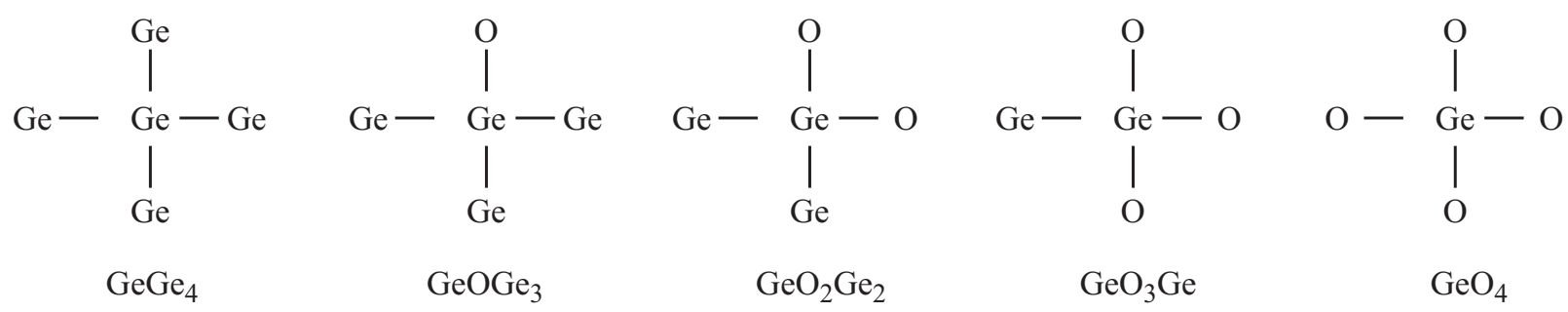

Рис. 5. Схематичное изображение тетраэдров, из которых состоит структура пленки $\mathrm{GeO}$ согласно модели случайных связей.

чений энергии связи $\sim 31.1 \pm 0.1$ эВ можно приписать германию в составе стехиометрического оксида $\mathrm{GeO}$ (тетраэдр $\mathrm{GeO}_{2} \mathrm{Ge}_{2}$ ) [19]. Кроме двух указанных пиков, в РФЭС-спектре имеется дополнительное плечо со стороны более низких значений энергии связи $\sim 29.5 \pm 0.1$ эВ, которое относится к фазе германия (тетраэдр $\mathrm{GeGe}_{4}$ ).

\section{4. Обсуждение результатов}

Экспериментальные данные свидетельствуют в пользу того, что структура твердого монооксида германия ближе всего соответствует модели случайных связей (random bonding (RB) model), без формирования обнаруженных кластеров германия. В частности, в спектре КРС пленки $\mathrm{GeO}$ не выявлено колебательных мод, характерных для связей $\mathrm{Ge}-\mathrm{Ge}$ в концентрации, достаточной для обнаружения (рис. 2, спектр 1). Прямое наблюдение структуры пленки $\mathrm{GeO}$ в электронном микроскопе подтвердило отсутствие в ней нанокластеров Ge. В ИК-спектре поглощения пленки $\mathrm{GeO}$ присутствует основная широкая полоса в области $770 \mathrm{~cm}^{-1}$ (рис. 3, спектр 1), связанная с валентными асимметричными колебаниями кислорода в мостике $\mathrm{Ge}-\mathrm{O}-\mathrm{Ge}$. При отжигах пленки $\mathrm{GeO}$ полоса поглощения монотонно сдвигалась в сторону больших частот колебаний, повышая свою интенсивность (рис. 3). Это можно объяснить тем, что за счет декомпозиции монооксида германия происходит перегруппировка решетки твердого материала. При низких температурах $\left(T<400^{\circ} \mathrm{C}\right)$ диффузионный массоперенос в пленке $\mathrm{GeO}$ способен осуществляться только с помощью механизма трансляции оборванных вакантных связей между соседними атомами решетки, который типичен для стекол $\mathrm{SiO}_{2}$ и $\mathrm{GeO}_{2}$ [14]. Окружение вокруг атомов $\mathrm{Ge}$ постепенно изменяется, а значит, меняются и частоты колебаний. С ростом времени и температуры отжигов концентрация кислорода в одних областях приближается к стехиометрии $\mathrm{GeO}_{2}$ (это нанообласти матрицы $\mathrm{GeO}_{2}$ ), а в других - снижается до нуля (это $\mathrm{Ge}-$ нанокластеры). Монотонное смещение пика качественно свидетельствует в пользу модели RB. При температуре от $260^{\circ} \mathrm{C}$ и выше структура пленки $\mathrm{GeO}$ начинает трансформироваться в структуру, которую можно описать моделью случайных фаз (random mixture (RM) model). В случае полного распада пленка $\mathrm{GeO}$ будет содержать кристаллическую фазу $\mathrm{Ge}$ и стеклообразную фазу $\mathrm{GeO}_{2}$ с мольным соотношением 1:1 [20].

В рамках модели случайных связей структуру аморфного стехиометрического монооксида германия $\mathrm{GeO}_{x}$ $(x=1)$ можно представить в виде сочлененных тетраэдров типа $\mathrm{GeGe}_{4}, \mathrm{GeOGe}_{3}, \mathrm{GeO}_{2} \mathrm{Ge}_{2}, \mathrm{GeO}_{3} \mathrm{Ge}, \mathrm{GeO}_{4}$, при этом атомы кислорода случайным образом распределены по объему матрицы (рис. 5). Функцию распределения тетраэдров $\mathrm{GeO}_{v} \mathrm{Ge}_{4-v}(v=0,1,2,3,4)$ в решетке $\mathrm{GeO}_{x}(x=1)$ можно задать уравнением, которое описывает вероятность распределения тетраэдров в субоксидах кремния для модели случайных связей [21]:

$$
W(v, x)=\left(\frac{x}{2}\right)^{v} \cdot\left(1-\frac{x}{2}\right)^{4-v} \cdot \frac{4 !}{v !(4-v) !} .
$$

Таким образом, вероятность обнаружить в пленке $\mathrm{GeO}_{x}(x=1)$ тетраэдр $\mathrm{GeGe}_{4}$ составляет $\frac{1}{16}(6.25 \%)$, $\mathrm{GeOGe}_{3}-\frac{4}{16}(25 \%), \mathrm{GeO}_{2} \mathrm{Ge}_{2}-\frac{6}{16}(37.5 \%), \mathrm{GeO}_{3} \mathrm{Ge}-$ $\frac{4}{16}(25 \%), \mathrm{GeO}_{4}-\frac{1}{16}(6.25 \%)$.

Данные РФЭС частично подтверждают наши предположения о структуре $\mathrm{GeO}$. Разложение спектра на отдельные компоненты показало, что доля чистого германия (6\%) в пленке $\mathrm{GeO}$ точно соответствует модели $\mathrm{RB}$ (рис. 4). Доля тетраэдров $\mathrm{GeO}_{2} \mathrm{Ge}_{2}$ слегка превышает требуемое количество (42\% вместо $37.5 \%$ ). Доля диоксида германия (52\%) значительно больше, чем в модели RB (6\%). Это расхождение можно объяснить тем, что исследуемая пленка $\mathrm{GeO}$ при хранении на воздухе может окисляться до $\mathrm{GeO}_{2}$ в приповерхностном слое (предположительно, до $\sim 1-2$ нм). Как известно, метод РФЭС собирает сигнал с верхнего слоя пленки толщиной $\sim 3-5$ нм, что и могло повлиять на полученные результаты. К сожалению, вследствие метастабильности пленки $\mathrm{GeO}$ невозможно было использовать ее травление ионами аргона, чтобы исследовать не только приповерхностную область. По-видимому, положение пика от германия в составе тетраэдра $\mathrm{GeO}_{3} \mathrm{Ge}$ близко к положению интенсивного пика $\mathrm{GeO}_{4}$, что не позволяет его разрешить. Тем не менее наличие весьма малого количества тетраэдров $\mathrm{GeGe}_{4}$ (по данным РФЭС) подтверждает данные спектроскопии КРС о том, что в исходных пленках $\mathrm{GeO}$ нет достаточно крупных кластеров германия. Наличие большого количества „Промежуточных“ связей $\left(\mathrm{GeO}_{2} \mathrm{Ge}_{2}\right.$, а также, возможно, $\mathrm{GeOGe}_{3}$ и $\left.\mathrm{GeO}_{3} \mathrm{Ge}\right)$ свидетельствует в пользу модели случайных связей. 
Согласно уравнению (1), с наибольшей вероятностью в решетке $\mathrm{GeO}_{x}(x=1)$ можно обнаружить тетраэдры с конфигурацией $\mathrm{GeO}_{2} \mathrm{Ge}_{2} . \mathrm{GeO}_{3} \mathrm{Ge}, \mathrm{GeOGe}_{3}$. По литературным данным, длина связей $\mathrm{Ge}-\mathrm{Ge}$ в решетке $\mathrm{GeO}$ составляет $\sim 3.23 \AA$, а связи $\mathrm{Ge}-\mathrm{O} \sim 1.92 \AA[13]$. Из-за различия в длине сторон большая часть тетраэдров решетки $\mathrm{GeO}$ оказывается неправильной, сильно деформированной, с искаженными угловыми параметрами. Деформации жестко ориентированных ковалентных $s p^{3}$-гибридных электронных орбиталей вызывают рост энергии внутренних напряжений атомной сетки. Это типично для материалов, чей базовый элемент решетки имеет низкую степень симметрии. При заполнении такими элементами пространства путем последовательных трансляций в формируемой сплошной атомной сетке $\mathrm{GeO}$ образуются большие полости, не заполненные этим веществом, либо для их заполнения возникнет сильная деформация тетраэдров. Этим можно объяснить неспособность твердого монооксида германия сохранять свою аморфную структуру при незначительных внешних воздействиях. Для высвобождения избыточной внутренней энергии он легко распадается на материалы с более устойчивым каркасом - $\mathrm{Ge}$ и $\mathrm{GeO}_{2}$, но при этом сохраняется тетраэдрическая структура.

\section{5. Заключение}

В работе проведено исследование структуры тонких пленок $\mathrm{GeO}$ стехиометрического состава с помощью оптических и электронно-микроскопических методов. Атомную структуру пленок монооксида германия можно описать моделью случайных связей. Установлена температура порога декомпозиции тонких пленок $\mathrm{GeO}$, которая составляет $\sim 260^{\circ} \mathrm{C}$. Наличие внутренних механических напряжений в атомной сетке $\mathrm{GeO}$, выстроенной из некомпактных тетраэдров $\mathrm{GeO}_{2} \mathrm{Ge}_{2}, \mathrm{GeO}_{3} \mathrm{Ge}, \mathrm{GeOGe}_{3}$, может приводить к его метастабильности.

\section{Благодарности}

Авторы благодарны А.Г. Черкову за проведение ВРЭМ-исследований и И.П. Просвирину за измерение РФЭС-спектров пленки $\mathrm{GeO}$.

\section{Финансирование работы}

РФЭС исследования пленки $\mathrm{GeO}$ проводились при поддержке Российского научного фонда (грант № 18-49-08001). В части измерения спектров КРС работа поддержана Министерством образования и науки РФ (проект 2020-1902-01-058). Работа частично выполнена с использованием оборудования Центра коллективного пользования „Наноструктуры“ Института физики полупроводников СО РАН и Центра коллективного пользования „Высокие технологии и аналитика наносистем“ Новосибирского государственного университета.

\section{Конфликт интересов}

Авторы заявляют, что у них нет конфликта интересов.

\section{Список литературы}

[1] C.H. Cheng, A. Chin, F.S. Yeh. Symp. VLSI Technol., Dig. Tech. Pap. (Honolulu, Hawaii, 2010) p. 85.

[2] V.A. Volodin, G.N. Kamaev, V.A. Gritsenko, A.A. Gismatulin, A. Chin, M. Vergnat. Appl. Phys. Lett., 114, 233104 (2019).

[3] A.V. Shaposhnikov, T.V. Perevalov, V.A. Gritsenko, C.H. Cheng, A. Chin. Appl. Phys. Lett., 100, 243506 (2012).

[4] V.A. Volodin, G.N. Kamaev, M. Vergnat. Phys. Status Solidi RRL, 14, 2000165 (2020).

[5] И.В. Тананаев, М.Я. Шпирт. Химия германия (М., Химия, 1967) гл. 4, с. 102.

[6] Н.А. Васютинский, Ю.И. Рысьева, Г.И. Петров, А.П. Сидоренко. Неорг. матер., 1 (7), 1057 (1965).

[7] А.П. Мартыненко, В.С. Крюков, Б.В. Стрижков, К.Г. Марин. Неорг. матер., 9 (9), 1568 (1973).

[8] Е.Б. Горохов, В.В. Грищенко. В сб.: Эллипсометрия: теория, методы, приложения (Новосибирск, Наука, 1987) c. 147.

[9] K. Prabhakaran, F. Maeda, Y. Watanabe, T. Ogino. Appl. Phys. Lett., 76 (16), 2244 (2000).

[10] И.Г. Стоянова, А.А. Тимофеев, А.Н. Зелянина, В.Н. Рыбаков, И.Ф. Анискин, З.А. Маслова, Н.М. Моисеева. Электрон. техн., сер. III, Микроэлектроника, 1, 71 (1972).

[11] D.V. Sheglov, E.B. Gorokhov, V.A. Volodin, K.N. Astankova, A.V. Latyshev. Nanotechnology, 19 (24), 245302 (2008).

[12] Д.А. Джишиашвили, В.В. Гобронидзе, З.В. Беришвили, 3.Н. Шиолашвили, Г.А. Схиладзе, Л.Г. Сахвадзе. Тр. Междунар. конф. „Современные информационные и электронные технологии“ (Одесса, Украина, 2005) с. 371.

[13] S.G. Ellis. J. Appl. Phys., 28 (11), 1262 (1957).

[14] Laser pulses - theory, technology, and applications, ed. by I. Peshko (Rijeka, InTech., 2012) v. 13, p. 383.

[15] В.В. Стрекалов. Автореф. маг. дис. (Новосибирск, Новосибирский гос. технический ун-т, 2014).

[16] В.А. Володин, В.А. Гриценко, А. Chin. Письма ЖТФ, 44 (10), 37 (2018).

[17] W. Sun, G. Zhong, C. Kubel, A.A. Jelle, C. Qian, L. Wang, M. Ebrahimi, L.M. Reyes, A.S. Helmy, G.A. Ozin. Angew. Chem. Int. Ed., 56, 6329 (2017).

[18] M. Ardyanian, H. Rinnert, X. Devaux, M. Vergant. Appl. Phys. Lett., 89, 011902 (2006).

[19] Y. Negishi, S. Nagao, Y. Nakamura, A. Nakajima. J. Appl. Phys., 88 (10), 6037 (2000).

[20] K.N. Astankova, E.B. Gorokhov, I.A. Azarov, V.A. Volodin, A.V. Latyshev. Surfaces and Interfaces, 6, 56 (2017).

[21] В.А. Гриценко. УФН, 178 (7), 727 (2008).

Редактор А.Н. Смирнов 


\section{About the structure of germanium monoxide thin films}

K.N. Astankova1, V.A. Volodin ${ }^{1,2}$, I.A. Azarov 1,2

${ }^{1}$ Institute of Semiconductor Physics,

Siberian Branch of Russian Academy of Sciences,

630090 Novosibirsk, Russia

${ }^{2}$ Novosibirsk State University,

630090 Novosibirsk, Russia

Abstract By means of optical (Raman spectroscopy, IR spectroscopy, XPS) and electron microscopic methods, it was found that the atomic structure of stoichiometric germanium monoxide films corresponds to the random bonding model, without the formation of germanium nanoclusters. This structure is metastable and transforms into a random mixture at a temperature higher than $260^{\circ} \mathrm{C}$. The metastability of solid $\mathrm{GeO}$ may be related to the presence of internal mechanical stresses in the atomic network. 